\title{
Rapid Spectrophotometric Methods for the Determination of Moxifloxacin and Sildenafil in Pharmaceutical Preparations Based on Reaction with 4-Aminoantipyrine
}

\section{Safwan Ashour*}

Faculty of Engineering, University of Gaziantep, Gaziantep, Turkey

*Corresponding Author: Safwan Ashour, Faculty of Engineering, University of Gaziantep, Gaziantep, Turkey.
Received: January 28, 2020

Published: March 09, 2020

(C) All rights are reserved by Safwan Ashour.

\begin{abstract}
Two simple and rapid spectrophotometric methods by the application of oxidative coupling reactions in aqueous medium for the determination of moxifloxacin hydrochloride (MOXF) and sildenafil citrate (SC) in either pure form or in its pharmaceutical preparations have been carried out. MOXF and SC react with 4-aminoantipyrine in the presence of $\mathrm{KIO}_{4}$ to yield red colored products exhibit maximum absorption at 530 and $526 \mathrm{~nm}$ for MOXF and SC, respectively. Beer's law plot showed linear relationship in the concentration ranges $2.65-230.0$ and $1.66-98.0 \mu \mathrm{g} / \mathrm{mL}$ with detection limit of 0.55 and $0.44 \mu \mathrm{g} / \mathrm{mL}$ for MOXF and SC, respectively. Molar absorptivity for the above two methods were found to be $4.40 \times 10^{3}$ and $8.25 \times 10^{3} \mathrm{~L} / \mathrm{mol} \mathrm{cm}$, respectively. The developed methods were applied to estimate MOXF and SC in tablets dosage form and the results compare favorably with those of pharmacopeial methods. Both the methods are accurate, precise and highly reproducible, cheap, rapid and suitable applied for routine analysis of MOXF and SC in bulk and formulations.
\end{abstract}

Keywords: 4-Aminoantipyrine; Moxifloxacin Hydrochloride; Sildenafil Citrate; Oxidative Coupling Reactions; Spectrophotometry; Dosage Forms

\section{Introduction}

Moxifloxacin (MOXF), 1-cyclopropyl-6-fluoro-1,4-dihydro-8methoxy-7- [(4aS,7aS)-octahydro- 6H-pyrrolo [3,4-b] pyridin-6-yl] 4-oxo-3-quinoline carboxylic acid [1] is an antibiotic prescription medicine for the treatment of certain bacterial infections [2]. British Pharmacopoeia (BP) describes HPLC method for the assay of moxifloxacin hydrochloride in pharmaceutical preparations [3]. Other methods in common use for estimation of moxifloxacin hydrochloride in pharmaceutical and biological samples involved high performance liquid chromatography [4,5], HPTLC [6], spectrophotometry [7-10], atomic absorption spectroscopy $[9,10]$, conductometry [9], kinetics spectrophotometry [10,11], extractive spectrophotometry [12], polarography [13], spectrofluorimetry [14], flow injection with chemiluminescence detection [15].

Sildenafil citrate (SC) is 1-[[3-(6,7-dihydro-1-methyl-7-oxo-3 propyl-1H-pyrazole [4,3-d] pyrimidin-5-yl)-4-ethoxyphenyl] sulfonyl]-4-methylpiperazine citrate [1]. It is phosphodiesterase-5 inhibitors used for erectile dysfunction. USP describes HPLC method for the examine sildenafil citrate [16]. Sildenafil citrate was determined by different methods including HPLC in pharmaceutical products $[17,18]$, HPLC in Pharmaceutical products with other drugs [19,20], HPLC in dietary supplements [21], CGC in pharmaceutical formulations and dietary supplements [22,23], HPTLC in commercial lifestyle products [24], electroanalytical methods in pharmaceutical preparations [25-27] and flow injection analysis in tablets using UV-detection [28] and amperometric detection [29]. Spectrophotometric methods, such as spectrophotometry through ion-associate formation reactions [30,31], ion-pair reactions [30,32], charge-transfer complexes [33], extractive spectrophotometry [34] and direct UV-spectrophotometry [35] were also communicated for the analysis of sildenafil citrate in pharmaceuticals.

The topical of our work is to evolve methods based on reaction of moxifloxacin hydrochloride and sildenafil citrate with 4-amino- 
antipyrine (4-AP) in the presence of an oxidizing agent (potassium periodate) in aqueous medium, and then spectrophotometric determination of moxifloxacin hydrochloride and sildenafil citrate in raw materials and tablets.

\section{Materials and Methods}

\section{Instrumentation}

Bioteck digital spectrophotometer (England) provided with matched $10 \mathrm{~mm}$ quartz cells was used for all spectral measurements of the resulting solutions.

\section{Chemicals and reagents}

Moxifloxacin hydrochloride pure material was obtained from Matrix Laboratories Limited (India). Its purity was evaluated and found to be $99.85 \%$ [3]. Sildenafil citrate pure material was obtained from Cipex Specialities Pvt Ltd., Mumbai (India). Its purity was evaluated as 99.83\% [16]. Tablets were purchased from Syrian market. All chemicals used were of AR grade and bidistilled water was used to prepare all the solutions. Aqueous solutions of $1 \times 10^{-2}$ M 4-aminoantipyrine (Ferack) and $1 \times 10^{-2} \mathrm{M} \mathrm{KIO}_{4}(\mathrm{BDH})$ were prepared daily. All the solutions were stored in the refrigerator and found to be stable for one week at least.

\section{Standard drug solutions}

Standard stock solutions of MOXF (1.0 mg/mL) and SC $(0.5 \mathrm{mg} /$ $\mathrm{mL}$ ) were prepared in double distilled water. A suitable dilution of the standard solution with bidistilled water was made to prepare working standard solutions.

\section{Reaction stoichiometry}

The stoichiometric ratio of the complexes formed was studied by continuous variation (Job's method) and molar ratio method [36]. $1 \times 10^{-3} \mathrm{M}$ of drug and $1 \times 10^{-2} \mathrm{M}$ of 4 -AP solutions were utilized. In the molar ratio method a constant volume of $1 \times 10^{-3} \mathrm{M}$ drug solution was treated with varying volume of 4-AP to obtain a ratio for the complex $(0: 1,0.1: 0.9,0.2: 0.8, \ldots . ., 1: 0)$, while in Job's method, a series of drug-reagent solutions was prepared to obtain a ratio for the ion pair complex $(0: 1,0.1: 0.9,0.2: 0.8, \ldots \ldots, 1: 0)$ where $\mathrm{C}_{\text {drug }}+\mathrm{C}_{4-\mathrm{AP}}$ $=2.0 \times 10^{-3} \mathrm{M}$. The absorbance of the resulting solutions was measured at $l_{\max }$ against the reagent blanks treated similarly.

\section{Formation constant $\left(\mathrm{K}_{\mathrm{f}}\right)$ and the standard free energy $\left(\Delta \mathrm{G}^{0}\right)$ of} colored species

The formation constant $\left(\mathrm{K}_{\mathrm{f}}\right)$ of the complexes MOXF-4AP and SC$4 \mathrm{AP}$ was evaluated spectrophotometricaly by substituting the data of Job's method in the equation (1).

$$
\mathrm{K}_{\mathrm{f}}=\frac{\mathrm{A} / \mathrm{A}_{\mathrm{m}}}{\left[1-\left(\mathrm{A} / \mathrm{A}_{\max }\right)\right]^{\mathrm{n}+2} \cdot \mathrm{C}_{\mathrm{M}}(\mathrm{n})^{\mathrm{n}}}
$$

Where $\mathrm{A}$ is the maximum observed absorbance and $\mathrm{A}_{\mathrm{m}}$ is the absorbance value when all the amount of drug is associated. $C_{M}$ is the mole concentration of drug at the maximum absorbance and $n$ is the combination ratio of the ion-pair considered [37].

The equation (2) represents the relation between Gibbs free en$\operatorname{ergy}\left(\Delta G^{\circ}\right)$ of the reaction product and the formation constant. This equation was used to calculate $\Delta G^{\circ}$ [38]:

$\Delta \mathrm{G}^{\mathrm{o}}=-2.303 \mathrm{RT} \log \mathrm{K}$

Where $\Delta G^{\circ}$ is the free energy change of the complex, $R$ is the gas constant $1.987 \mathrm{cal} / \mathrm{mol}$ degree, $T$ is the temperature in Kelvin, $K$ is the association or formation constant of drug-reagent complex (L/ mol).

\section{Validation of the proposed methods}

The methods were validated in accordance with the International Conference on Harmonization (ICH) guidelines [39].

Linearity

To determine MOXF, five separate series of MOXF solutions were prepared and analyzed. Aliquots of 0.085-2.00 mL standard solution of MOXF (2.65 - $230.0 \mu \mathrm{g} / \mathrm{mL}, 1.0 \mathrm{mg} / \mathrm{mL})$ were transferred into a series of $10 \mathrm{~mL}$ calibrated volumetric flasks. $2.0 \mathrm{~mL}$ of $0.01 \mathrm{M}$ 4-AP was added into each flask and kept aside for $4 \mathrm{~min}$. Finally, 2.0 $\mathrm{mL}$ of $0.01 \mathrm{M} \mathrm{KIO}_{4}$ was added and the volume was made up to the mark with bidistilled water. The content of flasks were mixed and the absorbance of the resulting colored solutions were measured at $530 \mathrm{~nm}$ against a similar reagent blank within a period of $10 \mathrm{~min}$.

For the determination of SC, five separate series of solutions of SC were prepared and analyzed. Aliquots of 0.067-1.96 mL standard solution of SC (1.66 - $98.0 \mu \mathrm{g} / \mathrm{mL}, 0.5 \mathrm{mg} / \mathrm{mL})$ were transferred into a series of $10 \mathrm{~mL}$ calibrated volumetric flasks. $1.4 \mathrm{~mL}$ of $0.01 \mathrm{M} 4-\mathrm{AP}$ and $0.8 \mathrm{~mL}$ of $0.01 \mathrm{M} \mathrm{KIO}_{4}$ were added into each flask and kept aside for $2 \mathrm{~min}$. The volume was made up to the mark with bidistilled water. The content of flasks were mixed and the absorbance of the resulting colored solutions were measured at $526 \mathrm{~nm}$ against a similar reagent blank within a period of $10 \mathrm{~min}$.

The standard curve of absorbances versus concentration was constructed for the determination of MOXF and SC. The obtained 
graph by least-squares method is described by regression equation, $\mathrm{A}=\mathrm{mC}+\mathrm{b}$ (where $\mathrm{A}$ is the absorbance of a $1 \mathrm{~cm}$ layer, $\mathrm{m}$ is the slope, $\mathrm{b}$ is the intercept and $\mathrm{C}$ is the concentration of the cited drug in $\mu \mathrm{g} / \mathrm{mL}$ ] [40].

\section{Sensitivity}

The limit of detection (LOD) and limit of quantification (LOQ) of the drugs were obtained experimentally by calculating the signal to-noise $(\mathrm{S} / \mathrm{N})$ ratio (i.e. 3.3 for $\mathrm{LOD}$ and 10 for $\mathrm{LOQ}$ ) using the formula:

$\mathrm{LOD}=3.3 \times \mathrm{S}_{\mathrm{a}} / \mathrm{b}$
$\mathrm{LOQ}=10 \times \mathrm{S}_{\mathrm{a}} / \mathrm{b}$

Where $S_{\mathrm{a}}$ is the standard deviation of the intercept and $b$ is the slope of the calibration curve [41].

\section{Precision}

Precision of the methods was established as repeatability. Various degrees of drug concentrations were prepared and analyzed as discussed above. The percent relative standard deviation (\% RSD) of the anticipated concentrations from the regression equation was taken as precision (Table 1).

\section{Accuracy}

For accuracy assays the same different levels of drug concentrations mentioned above were analyzed by the proposed methods and the percentage relative error and mean percentage recovery were calculated (Table 2).

The accuracy and specificity of the proposed methods were tested by recovery experiments of the formulations and the proposed methods were followed. From the amount of drug found, percentage recovery was calculated (Table 3).

\section{Procedure for formulations}

A total 20 tablets of each MOXF formulation were accurately weighed and pulverized. An amount of the powder equivalent to $50 \mathrm{mg}$ MOXF was transferred to $100 \mathrm{~mL}$ measuring flasks, $25 \mathrm{~mL}$ of methanol was added and shacked in ultrasonic bath for about $5 \mathrm{~min}$. The solutions were filtered through Whatman filter paper number 40 into separate $50 \mathrm{~mL}$ measuring flasks. The methanol was evaporated and the residue of solution was diluted to the volume with bidistilled water to achieve a concentration of $1 \mathrm{mg} / \mathrm{mL}$. the samples were analyzed using proposed method.
20 tablets were weighed, crushed, and mixed in a mortar and pestle. A portion of the powdered tablets equivalent to the weight of one tablet was accurately weighed and transferred into a 100 $\mathrm{mL}$ measuring flask and made up to the volume with bidistilled water to achieve a concentration of $0.5 \mathrm{mg} / \mathrm{mL}$. The solution was mixed well and filtered. The solution was further diluted stepwise with bidistilled water to get working solutions and analyzed as described earlier.

\section{Robustness}

Robustness was tested by evaluating the influence of a small variation of the method variables including the concentration of analytical reagents, reaction time and temperature on the performance of the proposed methods. In these experiments, one parameter was changed whereas the others were kept unchanged, and the recovery percentage was calculated each time.

\section{Results and Discussion}

\section{Absorption spectra}

An intense red-coloured oxidizing coupling products with an absorption maximum at 530 and $526 \mathrm{~nm}$ are formed when MOXF and SC, respectively, were allowed to react with 4-AP in the presence of $\mathrm{KIO}_{4}$ as an oxidant in aqueous medium. Figure 1 shows the spectra of red products formed and of the reagent blanks. The absorbance is directly related to concentration of MOXF and SC and can be used for its spectrophotometric determination.

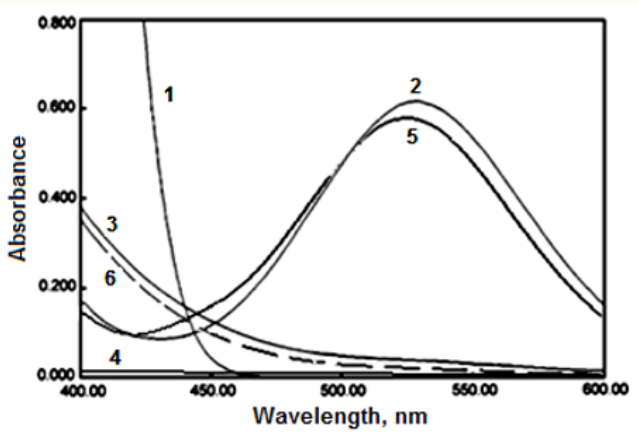

Figure 1: Absorption spectra of (1) $100 \mu \mathrm{g} / \mathrm{mL}$ of MOXF against distilled water, (2) MOXF (150 $\mu \mathrm{g} / \mathrm{mL})-4 \mathrm{AP}\left(2 \mathrm{~mL}\right.$ of $\left.10^{-2} \mathrm{M}\right)-\mathrm{KIO}_{4}$ ( $2 \mathrm{~mL}$ of $10^{-2} \mathrm{M}$ ) system against reagent blank (3) against distilled water, (4) $66 \mu \mathrm{g} / \mathrm{mL}$ of SC against distilled water, (5) SC (66 $\mu \mathrm{g}$ / $\mathrm{mL})-4 \mathrm{AP}\left(1.4 \mathrm{~mL}\right.$ of $\left.10^{-2} \mathrm{M}\right)-\mathrm{KIO}_{4}\left(0.8 \mathrm{~mL}\right.$ of $\left.10^{-2} \mathrm{M}\right)$ system against reagent blank (6) vs. distilled water. 
Rapid Spectrophotometric Methods for the Determination of Moxifloxacin and Sildenafil in Pharmaceutical Preparations Based on Reaction with 4-Aminoantipyrine

\section{Optimization of reaction conditions}

The influence of the variables on the absorption intensity of the species formed was studied and the reaction conditions are optimized. The optimum values of the variables were maintained throughout the experiment.

\section{Effect of temperature and order of addition}

The species products of the proposed methods were studied at different temperatures. The results indicate that the absorbance values remain constant at laboratory temperature $\left(25 \pm 2^{\circ} \mathrm{C}\right)$, whereas, at higher temperatures the absorbance value decrease, indicating the dissociation of the product on prolonged heating. Therefore room temperature is selected.

To obtain maximum absorbance and then optimum results the order of addition of reagents should be as follow: drug, 4-AP and $\mathrm{KIO}_{4}$, otherwise a loss in colour intensity was observed.

\section{Effect of reaction time}

The colour intensity reached its maximum within 5 min after the drug had been reacted with 4-AP in the presence of $\mathrm{KIO}_{4}$ and remains stable for $10 \mathrm{~min}$, therefore $5 \mathrm{~min}$ development time was selected as optimum in the general procedure.

\section{Effect of reagent concentration}

For maximum color development, various concentrations of 4-AP and $\mathrm{KIO}_{4}$ solutions were added to fixed amount of the drug solution. $2.0 \mathrm{~mL}$ of $0.01 \mathrm{M} 4-\mathrm{AP}$ and $2.0 \mathrm{~mL}$ of $0.01 \mathrm{M} \mathrm{KIO}_{4}$ solutions were found to be optimal for MOXF, while $1.4 \mathrm{~mL}$ of $0.01 \mathrm{M} \mathrm{4-AP}$ and $0.8 \mathrm{~mL}$ of $0.01 \mathrm{M} \mathrm{KIO}_{4}$ solutions were found to be enough for $\mathrm{SC}$, to develop the colour to its full intensity and give a minimum blank value and was considered to be optimum for concentration range of 2.65 - 230.0 and 1.66-98.0 $\mu \mathrm{g} / \mathrm{ml}$ of MOXF and SC, respectively (Figure 2).

\section{Stoichiometric relationship}

Job's method using equimolar solutions of MOXF and SC and 4-AP was applied to know the composition of MOXF-4AP and SC4AP colored species. The method revealed 1:2 and 1:1 molar ratio (drug to 4-AP) for MOXF (Figure 3A) and 1:1 for SC (Figure 4A). Also, the mole-ratio method showed the formation of $1: 1$ and $1: 2$ for MOXF (Figure 3B) and 1:1 for SC (Figure 4B).
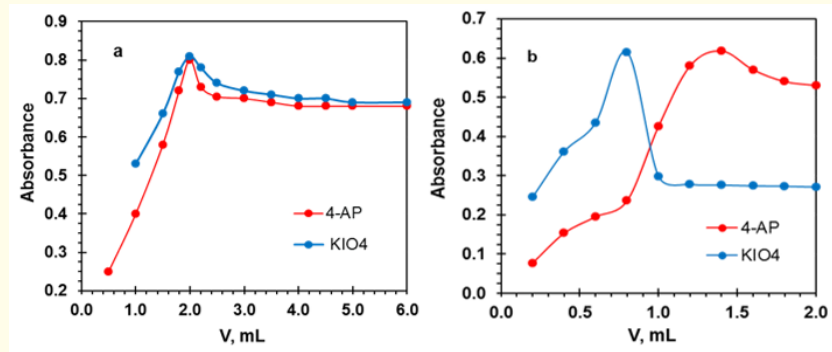

Figure 2: Effect of concentration of (a) 4-AP in the presence of 2.0 $\mathrm{mL}$ of 10-2 $\mathrm{M} \mathrm{KIO}_{4}$ and $\mathrm{KIO}_{4}$ in the presence of $2.0 \mathrm{~mL}$ of $10-2 \mathrm{M}$ 4-AP on the formation of MOXF $(200 \mu \mathrm{g} / \mathrm{mL})-4 \mathrm{AP}-\mathrm{KIO}_{4}$ system. (b) 4-AP in the presence of $0.8 \mathrm{~mL}$ of $10-2 \mathrm{M} \mathrm{KIO}_{4}$ and $\mathrm{KIO} 4$ in the presence of $1.4 \mathrm{~mL}$ of $10^{-2} \mathrm{M} 4-\mathrm{AP}$ on the formation of SC $(75 \mu \mathrm{g} /$ $\mathrm{mL})-4 \mathrm{AP}-\mathrm{KIO}_{4}$ system.
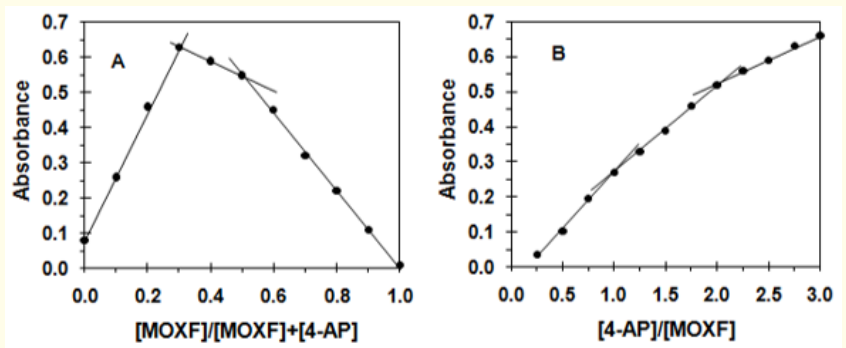

Figure 3: (A) Job's method of continuous variations of MOXF-4AP product: $\mathrm{C}_{\mathrm{MOXF}}+\mathrm{C}_{4 \mathrm{AP}}=2.0 \times 10^{-3} \mathrm{M}$. (B) Mole-ratio method of MOXF$4 \mathrm{AP}$ product, $\mathrm{C}_{\text {MOXF }}=5 \times 10^{-4} \mathrm{M}$.
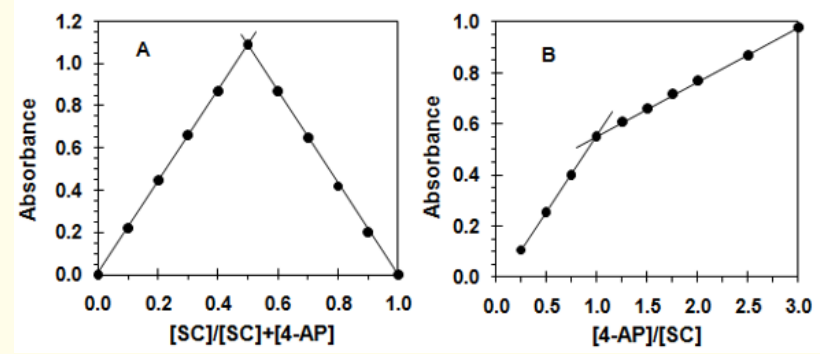

Figure 4: (A) Job's method of continuous variations of SC-4AP product: $\mathrm{C}_{\mathrm{SC}}+\mathrm{C}_{4 \mathrm{AP}}=2.0 \times 10^{-3} \mathrm{M}$. (B) Mole-ratio method of SC-4AP product, $\mathrm{C}_{\mathrm{SC}}=5 \times 10^{-3} \mathrm{M}$. 
Rapid Spectrophotometric Methods for the Determination of Moxifloxacin and Sildenafil in Pharmaceutical Preparations Based on Reaction with 4-Aminoantipyrine

4-aminoantipyrine in the presence of potassium periodate, undergoes oxidation with loss of two protons and yields N-substituted quinone imine which in turn is known to spontaneously react with methoxy compounds to yield a red colored antipyrine dye [42]. The electrophilic intermediate couples with MOXF due to the presence of methoxy group by electrophilic attack on the nucleophilic site of the heterocyclic ring to the nitrogen and the resulting intermediate species is spontaneously oxidized with periodate to form the colored oxidative coupling product as shown in Scheme 1.

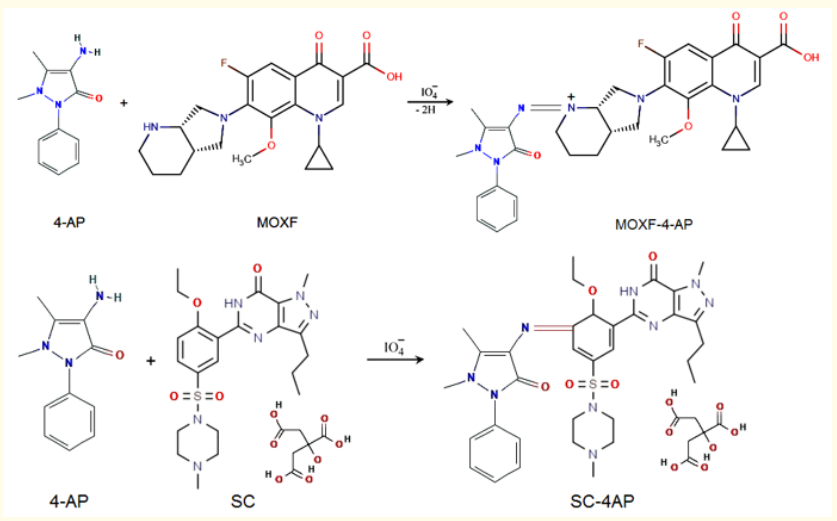

Scheme 1: Possible reaction of MOXF and SC with 4-AP in the presence of $\mathrm{KIO}_{4}$ solution.

The formation constant and the standard free energy

The formation constant $\left(K_{f}\right)$ and free energy $\left(\Delta G^{\circ}\right)$ values of MOXF-4AP and SC-4AP complexes were calculated using equations (1) and (2) and are tabulated in table 1. The negative values of $\Delta G^{\circ}$ indicate the stability of these complexes and their spontaneous formation.

\section{Validation of the proposed methods}

Linearity, LOD and LOQ

In quantitative analysis the calibration curve was constructed for both MOXF and SC after analysis of consecutively increased concentrations. Beer's law limits, molar absorptivity and Sandell's sensitivity values were determined for the developed methods and are given in Table 1. Regression analysis of the Beer's law plots reveals a good correlation. Limit of detection (LOD) and limit of quantification (LOQ) decide about the sensitivity of the method. LOD and LOQ for MOXF and SC were calculated according to the equations 3 and 4 , respectively. LOD was 0.55 and $0.44 \mu \mathrm{g} / \mathrm{mL}$ and LOQ was 1.65 and $1.33 \mu \mathrm{g} / \mathrm{mL}$ for MOXF and SC, respectively.

\begin{tabular}{|c|c|c|}
\hline Parameters & MOXF & SC \\
\hline$\lambda_{\max }(\mathrm{nm})$ & 530 & 526 \\
\hline $\begin{array}{l}\text { Beer's law range } \\
(\mu \mathrm{g} / \mathrm{mL})\end{array}$ & $2.65-230.0$ & $1.66-98.0$ \\
\hline $\begin{array}{l}\text { Molar absorptivity } \\
(\mathrm{L} / \mathrm{mol} \mathrm{cm})\end{array}$ & $4.40 \times 10^{3}$ & $8.25 \times 10^{3}$ \\
\hline $\begin{array}{l}\text { Ringbom optimum } \\
\text { photometric range } \\
(\mu \mathrm{g} / \mathrm{mL})\end{array}$ & $15.0-180.0$ & $10.0-70.0$ \\
\hline \multirow{2}{*}{$\begin{array}{l}\text { Formation constant, } \mathrm{K}_{\mathrm{f}} \\
(\mathrm{L} / \mathrm{mol})\end{array}$} & $3.16 \times 10^{4}(1: 1)$ & $1.79 \times 10^{8}(1: 1)$ \\
\hline & $6.31 \times 10^{8}(1: 2)$ & - \\
\hline$\Delta \mathrm{G}^{\circ}(\mathrm{Kcal} / \mathrm{mol})$ & $-6.14,-12.00$ & -11.25 \\
\hline $\mathrm{LOD}(\mu \mathrm{g} / \mathrm{mL})$ & 0.55 & 0.44 \\
\hline $\mathrm{LOQ}(\mu \mathrm{g} / \mathrm{mL})$ & 1.65 & 1.33 \\
\hline $\begin{array}{l}\text { Sandell's sensitivity } \\
\text { ( } \mu \mathrm{g} / \mathrm{cm}^{2} \text { per } 0.001 \text { abs } \\
\text { unit) }\end{array}$ & 0.092 & 0.081 \\
\hline Regression equation $^{a}$ & $\begin{array}{c}A= \\
0.0038 C+0.0388\end{array}$ & $\begin{array}{c}A= \\
0.0077 C+0.0439\end{array}$ \\
\hline $\begin{array}{l}\text { Correlation coefficient, } \\
\mathrm{r}\end{array}$ & 0.9999 & 0.9999 \\
\hline Mean $\%$ recovery \pm SD & $100.40 \pm 0.16$ & $100.12 \pm 0.22$ \\
\hline
\end{tabular}

Table 1: Optical characteristics of the proposed methods for MOXF and SC.

\section{Precision}

To check the precision and reproducibility of the method, six samples of the same concentration $(n=6)$ of MOXF and SC were prepared and analysed (Table 2). The low \%RSD values obtained for MOXF (0.52) and SC (0.11) indicated that the method had high precision and reproducibility.

\section{Accuracy}

Accuracy of the method for the analysis of MOXF and SC in its pure state was checked. The accuracy of the method indicated by the excellent recovery (Table 2).

The \% recovery for MOXF and SC were found to be in the range of $100.43-101.04 \%$ and $101.27-102.10 \%$, respectively, for the formulations tested (Table 3 ). The high recovery rate indicated that the method had a good accuracy and specificity, as there was no interference from the excipients present in formulations. 
Rapid Spectrophotometric Methods for the Determination of Moxifloxacin and Sildenafil in Pharmaceutical Preparations Based on Reaction with 4-Aminoantipyrine

\begin{tabular}{|c|c|c|c|c|c|}
\hline \multirow{2}{*}{ Drug } & \multicolumn{2}{|c|}{ mg/mL } & \multirow{2}{*}{ Relative error (\%) } & \multirow{2}{*}{ RSD (\%) } & \multirow{2}{*}{$\%$ Recovery \pm SD } \\
\hline & Taken & Found* & & & \\
\hline \multirow[t]{6}{*}{ MOXF } & 2.65 & 2.67 & 0.75 & 1.89 & $100.75 \pm 0.21$ \\
\hline & 20.00 & 20.15 & 0.75 & 1.52 & $100.75 \pm 0.19$ \\
\hline & 40.00 & 39.98 & -0.05 & 1.06 & $99.95 \pm 0.14$ \\
\hline & 80.00 & 80.17 & 0.21 & 0.92 & $100.21 \pm 0.17$ \\
\hline & 160.00 & 161.25 & 0.78 & 0.63 & $100.78 \pm 0.13$ \\
\hline & 200.00 & 199.73 & -0.14 & 0.52 & $99.86 \pm 0.15$ \\
\hline \multirow[t]{6}{*}{ SC } & 2.00 & 1.99 & -0.50 & 1.76 & $99.50 \pm 0.24$ \\
\hline & 5.00 & 5.01 & 0.20 & 0.82 & $100.20 \pm 0.22$ \\
\hline & 10.00 & 10.03 & 0.30 & 0.64 & $100.30 \pm 0.19$ \\
\hline & 20.00 & 20.05 & 0.25 & 0.51 & $100.25 \pm 0.21$ \\
\hline & 40.00 & 40.11 & 0.27 & 0.43 & $100.27 \pm 0.20$ \\
\hline & 80.00 & 80.23 & 0.28 & 0.11 & $100.28 \pm 0.26$ \\
\hline
\end{tabular}

Table 2: Analysis of MOXF and SC in bulk powder by the proposed method.

\section{Application to the pharmaceutical dosage forms}

The proposed methods were successfully applied to determine MOXF and SC in their commercial tablets. The concentration of the studied drugs was calculated using the corresponding calibration equation shown in Table 1 . The commonly used excipients and additives in the preparation of tablets were found not to interfere in the analysis. The \% recoveries of the two drugs in their tablets compared with those of the official methods of BP [3] and USP [16] for the studied drugs, respectively, are given in table 3 . The results were treated statistically. Since F-test and t-test showed that there was no significant difference between the proposed methods and the standard methods.

\begin{tabular}{|c|c|c|c|c|}
\hline \multirow{2}{*}{ Formulation } & \multicolumn{2}{|c|}{$\%$ Recovery \pm SD ${ }^{\text {a }}$} & \multirow{2}{*}{$t$-value ${ }^{b}$} & \multirow{2}{*}{$F$-value ${ }^{\text {b }}$} \\
\hline & Proposed method & Pharmacopeial method & & \\
\hline Moxicin ${ }^{c}(400 \mathrm{mg} /$ tablet $)$ & $100.43 \pm 0.23$ & $99.98 \pm 0.19$ & 1.68 & 1.46 \\
\hline Aviloxin ${ }^{\mathrm{d}}$ (400mg/tablet) & $101.04 \pm 0.29$ & $99.98 \pm 0.18$ & 1.84 & 2.59 \\
\hline Vaigran ${ }^{\mathrm{e}}(50 \mathrm{mg} /$ tablet $)$ & $102.08 \pm 0.17$ & $101.14 \pm 0.13$ & 1.96 & 1.71 \\
\hline Extra $^{\mathrm{f}}(50 \mathrm{mg} /$ tablet $)$ & $102.10 \pm 0.23$ & $100.53 \pm 0.17$ & 1.94 & 1.83 \\
\hline Vega $^{g}(50 \mathrm{mg} /$ tablet $)$ & $101.27 \pm 0.24$ & $100.83 \pm 0.19$ & 1.59 & 1.59 \\
\hline \multicolumn{5}{|c|}{$\begin{array}{l}\text { a. Five independent analyses. b. Theoretical values for } \mathrm{t} \text { and F-test at five degree of freedom and } 95 \% \\
\text { confidence limit are } t=2.776 \text { and } F=6.26 \text {. c. Supplied by Ibn Al Haytham, d. supplied by Ibn hayan, e. } \\
\text { supplied by Barakat Pharmaceutical Industry, f. supplied by adamco and g. supplied by Oubari Pharma, } \\
\text { Syria. }\end{array}$} \\
\hline
\end{tabular}

Table 3: Determination of MOXF and SC in tablets by the proposed and pharmacopeial methods.

\section{Robustness}

The robustness of the methods was studied by using five replicates at MOXF and SC concentration level of 100 and $75 \mu \mathrm{g} / \mathrm{mL}$, respectively. It was found that small variations in these variables did not affect the method significantly. This was an indication of the reliability of the proposed method during its routine application for analysis of the investigated drugs (Table 4). 
Rapid Spectrophotometric Methods for the Determination of Moxifloxacin and Sildenafil in Pharmaceutical Preparations Based on Reaction with 4-Aminoantipyrine

\begin{tabular}{|c|c|c|c|c|}
\hline \multirow{3}{*}{$\begin{array}{l}\text { Parameter variation } \\
\text { No Change }\end{array}$} & \multicolumn{4}{|c|}{ Recovery \% \pm SD ${ }^{\text {a }}$} \\
\hline & \multicolumn{2}{|r|}{ MOXF } & \multicolumn{2}{|r|}{ SC } \\
\hline & & $100.12 \pm 0.16$ & & $100.06 \pm 0.11$ \\
\hline \multirow[t]{2}{*}{ Change in 4-AP $0.01 \mathrm{M}$ volume } & $1.8 \mathrm{~mL}$ & $96.91 \pm 0.18$ & $1.3 \mathrm{~mL}$ & $98.71 \pm 0.12$ \\
\hline & $2.2 \mathrm{~mL}$ & $99.48 \pm 0.17$ & $1.5 \mathrm{~mL}$ & $97.41 \pm 0.14$ \\
\hline \multirow[t]{2}{*}{ Change in $\mathrm{KIO}_{4} 0.01 \mathrm{M}$ volume } & $1.8 \mathrm{~mL}$ & $96.94 \pm 0.19$ & $0.7 \mathrm{~mL}$ & $89.43 \pm 0.21$ \\
\hline & $2.2 \mathrm{~mL}$ & $97.45 \pm 0.15$ & $0.9 \mathrm{~mL}$ & $81.30 \pm 0.23$ \\
\hline \multirow[t]{2}{*}{ Change in measurement time } & $4 \mathrm{~min}$ & $97.85 \pm 0.11$ & $4 \mathrm{~min}$ & $96.09 \pm 0.17$ \\
\hline & $10 \mathrm{~min}$ & $100.08 \pm 0.14$ & $10 \mathrm{~min}$ & $100.11 \pm 0.13$ \\
\hline \multirow[t]{2}{*}{ Change in temperature } & $20^{\circ} \mathrm{C}$ & $99.97 \pm 0.13$ & $20^{\circ} \mathrm{C}$ & $100.01 \pm 0.15$ \\
\hline & $30^{\circ} \mathrm{C}$ & $100.09 \pm 0.16$ & $30^{\circ} \mathrm{C}$ & $100.05 \pm 0.14$ \\
\hline
\end{tabular}

Table 4: Results of robustness study of MOXF and SC.

\section{Conclusion}

The methods that are proposed in this work for the quantitation of moxifloxacin and sildenafil are simple, direct and sensitive. Moreover, they are less time consuming and do not require elaboration treatment and tedious extraction procedures required in chromatographic and other traditional extractive spectrophotometric methods. These, in addition to satisfactory sensitivity $(0.44$ $\mu \mathrm{g} / \mathrm{mL}$ ) and reproducibility compared to the official non-aqueous titrimetric methods, make the methods applicable for routine analysis of the two drugs both in pure form and in tablets.

\section{Bibliography}

1. Maryadele J., et al. "The Merck Index: An Encyclopedia of Chemicals, Drugs and Biologicals". 15th ed., Royal Society of Chemistry, Cambridge, UK (2013).

2. Barman Balfour JA., et al. "Moxifloxacin: a review of its clinical potential in the management of community-acquired respiratory tract infections". Drugs 59.1 (2000): 115-139.

3. British Pharmacopoeia, Her Majesty Stationery Officer, London, UK (2013).

4. Kumar Reddy GN., et al. "Development and validation of a stability indicating UPLC method for determination of moxifloxacin hydrochloride in pharmaceutical formulations". Pharmaceutica Analytica Acta 2.9 (2011): 1-10.

5. Ashour S., et al. "New, simple and validated RP-HPLC method for quality control of moxifloxacin". SOJ Pharmacy and Pharmaceutical Sciences 3.3 (2016): 1-6.
6. Motwani SK., et al. "Application of a validated stability-indicating densitometric thin-layer chromatographic method to stress degradation studies on moxifloxacin". Analytica Chimica Acta 582.1 (2007): 75-82.

7. Motwani SK., et al. "Validated spectrophotometric methods for the estimation of moxifloxacin in bulk and pharmaceutical formulations". Spectrochimica Acta Part A 68.2 (2007): 250-256.

8. Attimarad M., et al. "Simultaneous determination of moxifloxacin and cefixime by first and ratio first derivative ultraviolet spectrophotometry". Chemistry Central Journal 6 (2012): 1-7.

9. AL-Ghannam SM. "Atomic absorption spectroscopic, conductometric and colorimetric methods for determination of some fluoroquinolone antibacterials using ammonium reineckate". Spectrochimica Acta Part A 69.4 (2008): 1188-1194.

10. Abdellaziz LM., et al. "Development and validation of spectrophotometric, atomic absorption and kinetic methods for determination of moxifloxacin hydrochloride". Analytical Chemistry Insights 6 (2011): 67-78.

11. Ashour S., et al. "Development and validation of sensitive kinetic spectrophotometric method for the determination of moxifloxacin antibiotic in pure and commercial tablets". Spectrochimica Acta Part A 140 (2015): 216-222.

12. Gouda AA., et al. "Spectrophotometric determination of gemifloxacin mesylate, moxifloxacin hydrochloride, and enrofloxacin in pharmaceutical formulations using acid dyes". Journal of Analytical Methods in Chemistry (2014): 1-16. 
13. Inam R., et al. "Differential pulse polarographic determination of moxifloxacin hydrochloride in pharmaceuticals and biological fluids". Analytical Letter 40 (2007): 529-546.

14. Kamruzzaman M., et al. "Spectrofluorimetric study of the interaction between europium(III) and moxifloxacin in micellar solution and its analytical application". Spectrochimica Acta Part A 86 (2012): 375-380.

15. Ocaña JA., et al. "Application of lanthanide-sensitised chemiluminescence to the determination of levofloxacin, moxifloxacin and trovafloxacin in tablets". Microchimica Acta 144.1-3 (2004): 207-213.

16. The United States Pharmacopeia (USP 35), The National Formulary (NF 30), 5994 (2012).

17. Abd-ELbary A., et al. "Stability indicating high performance liquid chromatographic assay for the determination of sildenafil citrate in bulk and in formulations". Chromatographia 59.9-10 (2004): 561-566.

18. Molleti S., et al. "Determination of sildenafil citrate and its related substances in the commercial products and tablet dosage form using RP-UPLC". American Journal of PharmTech Research 3.2 (2013): 378-404.

19. Fidan AK., et al. "Simultaneous determination of sildenafil and tadalafil in legal drugs, illicit/counterfeit drugs, and wastewater samples by high-performance liquid chromatography". Journal of AOAC International 99.4 (2016): 923-928.

20. Kalyani K., et al. "A novel stability indicating RP-HPLC method for the simultaneous estimation of Sildenfii Citrate and Dapoxetine Hydrochloride in bulk and Pharmaceutical formulations". Der Pharmacia Letter 7.10 (2014): 98-106.

21. Li J., et al. "Solid-phase extraction assisted dispersive liquidliquid microextraction based on solidification of floating organic droplet to determine sildenafil and its analogues in dietary supplements". Journal of Separation Science 40.3 (2017): 3120-3129.

22. Berzas JJ., et al. "Validation of a capillary gas chromatographic method for the determination of sildenafil citrate in its pharmaceutical formulations (Viagra). Experimental design for evaluating the ruggedness of the method". Chromatographia 55.9/10 (2002): 601-606.

23. Mokhtar SU., et al. "Rapid determination of sildenafil and its analogues in dietary supplements using gas chromatographytriple quadrupole mass spectrometry". Journal of Pharmaceutical and Biomedical Analysis 121 (2016): 188-196.
24. Do TT., et al. "Simultaneous detection of three phosphodiesterase type 5 inhibitors and eight of their analogs in lifestyle products and screening for adulterants by high-performance thin-layer chromatography". Journal of AOAC International 98.5 (2015): 1226-1233.

25. Batista EF., et al. "Differential pulse voltammetric determination of sildenafil citrate (Viagra) in pharmaceutical formulations using a boron-doped diamond electrode". Analytical Letters 43 (2010): 1046-1054.

26. Farghali RA., et al. "Gold nanoparticles-modified screen-printed carbon electrode for voltammetric determination of sildenafil citrate (Viagra) in pure form, biological and pharmaceutical formulations". International Journal of Electrochemical Science 10.2 (2015): 1494-1505.

27. Güzel R., et al. "New voltammetric approach to the quantitative estimation of sildenafil citrate in tablets using disposable pencil graphite electrode". Sensor Letters 12.11 (2014): 16751681.

28. Altiokka G., et al. "FIA of sildenafil citrate using UV-detection". Journal of Pharmaceutical and Biomedical Analysis 25.2 (2001): 339-342.

29. Lopes Júnior ACV., et al. "Determination of sildenafil citrate (Viagra ${ }^{\circledR}$ ) in various pharmaceutical formulations by flow injection analysis with multiple pulse amperometric detection". Journal of Brazilian Chemical Society 23.1 (2012): 1800-1806.

30. Issa YM., et al. "Spectrophotometric determination of sildenafil citrate in pure form and in pharmaceutical formulation using some chromotropic acid azo dyes". Spectrochimica Acta Part A 75.4 (2010): 1297-1303.

31. Frag EYZ., et al. "Utility of ion-associate formation reactions for the spectrophotometric determination of sildenafil citrate in pure form and in Virecta tablets". Pharmaceutica Analytica Acta 2.6 (2011): 1-7.

32. Alhaj Sakur A., et al. "Simple and sensitive spectrophotometric determination of sildenafil citrate in pharmaceutical formulations". Research Journal of Pharmacy and Technology 10.12 (2017): 4242-4246.

33. Alhaj Sakur A., et al. "Validated spectrophotometric method to determine vardenafil and sildenafil in pharmaceutical forms using potassium iodide and potassium iodate". International Journal of Pharmacy and Pharmaceutical Sciences 9.11 (2017): 65-69. 
34. Harikrishna K., et al. "Extractive spectrophotometric determination of sildenafil citrate (Viagra) in pure and pharmaceutical formulations". Journal of Food and Drug Analysis 16.1 (2008): 11-17.

35. Sparsha N., et al. "Development of new and rapid method for UV spectrophotometric determination of sildenafil in marketed formulations". Der Pharmacia Lettre 4.6 (2012): 17561759.

36. Rose J. Advanced Physico-chemical Experiments, Pittman, London (1964): 67.

37. Ashour S., et al. "Sensitive extractional colorimetric analysis of fexofenadine hydrochloride and irbesartan bases through acid-dye complexation using naphthol blue black in pure form and pharmaceuticals". Modern Chemistry 5.6 (2017): 93-100.

38. Martin AN., et al. "Physical Pharmacy". Third Edition, Lee and Febiger, Philadelphia (1983): 344-346.

39. ICH, Q2 (R1). Validation of analytical procedures: text and methodology, International Conference on harmonization. Geneva (2005).

40. Miller JN., et al. "Statistics and Chemometrics for Analytical Chemistry". fifth ed., Chapman and Hall/CRC, London, UK (2005).

41. Long GL., et al. "Limit of Detection, A Closer Look at the IUPAC Definition". Analytical Chemistry 55 (1983): 712A.

42. Ayad M., et al. "4-Aminoantipyrine as an analytical reagent for the colorimetric determination of tetracycline and oxytetracycline”. Analytical Letters 19.21-22 (1986): 2169-2181.

\section{Assets from publication with us}

- Prompt Acknowledgement after receiving the article

- Thorough Double blinded peer review

- Rapid Publication

- Issue of Publication Certificate

- High visibility of your Published work

Website: www.actascientific.com/

Submit Article: www.actascientific.com/submission.php

Email us: editor@actascientific.com

Contact us: +919182824667 